\title{
Research on Failure Characteristics and Zoning Control Technology of Thick-Soft Surrounding Rock for Deep Gob-Side Entry Retaining
}

\author{
Jingke Wu $\mathbb{D}^{1,2,3}$ Wenbin Zhou ${ }^{1},{ }^{2}$ Hong Tao $\mathbb{D}^{2},{ }^{2}$ Haowen Bai ${ }^{1},{ }^{2}$ Wei Yin ${ }^{1},{ }^{1}$ \\ Wenhu Gu $\mathbb{1}$, ${ }^{1}$ Peng Zhang $\mathbb{1}$, ', Zejun Liu $\mathbb{1}^{1},{ }^{1}$ and Jiao Zhang $\mathbb{1}{ }^{4}$ \\ ${ }^{1}$ Jiangsu Engineering Laboratory of Assembly Technology on Urban and Rural Residence Structure, \\ Huaiyin Institute of Technology, Huai'an, Jiangsu 223001, China \\ ${ }^{2}$ Jiangsu Baoli International Investment Co., Ltd., Jiangyin, Jiangsu 214400, China \\ ${ }^{3}$ School of Transportation, Southeast University, Nanjing, Jiangsu 211189, China \\ ${ }^{4}$ School of Civil Engineering, Henan Polytechnic University, Jiaozuo, Henan 454000, China \\ Correspondence should be addressed to Jingke Wu; wujingke@hyit.edu.cn
}

Received 22 October 2020; Revised 4 November 2020; Accepted 11 November 2020; Published 23 November 2020

Academic Editor: Guangchao Zhang

Copyright (C) 2020 Jingke Wu et al. This is an open access article distributed under the Creative Commons Attribution License, which permits unrestricted use, distribution, and reproduction in any medium, provided the original work is properly cited.

Controlling the large deformation caused by bed separation failure of thick and soft surrounding rock in gob-side entry retaining is difficult. The deformation and failure modes of thick and soft surrounding rock are summarized and classified based on field research, theoretical analysis, laboratory tests, and actual measurements. Systematic research is conducted on the lithologic characteristics, failure characteristics, and control methods of the surrounding rock. The research findings are as follows: (1) The low strength, softening, and water swelling of thick mudstone, as well as its cataclasis, dilatancy, and long-term creep under strong mining and high stress are the objective reasons for large deformation of the surrounding rock. (2) Due to the weak stability of the surrounding rock-support structure and low collaborative roof side bearing capacity, no complete supporting structure is formed with the supporting system, causing the support body in each area to be crushed one by one, which is the subjective reason for the deformation and failure of the surrounding rock. (3) The deformation and failure characteristics of thick and soft surrounding rock in gob-side entry retaining are primarily divided into eight types: roof bending and sinking type, roof cutting along filling body, rib spalling type, roof fall type, filling body rotation type, filling body crushing type, roof step type, and roof cutting along the coal side. The initial points and key points for a chain reaction of each failure type are determined. (4) The surrounding rock is divided into 10 support zones at four levels, and control technology for "zonal support and overall reinforcement" is put forward. The mechanical effect of the support body in each zone and its role in maintaining the stability of surrounding rock are analyzed. This technology can ensure the integrity of the surrounding rock structure and improve the roof side collaborative bearing capacity.

\section{Introduction}

The Huainan Mining Area in Anhui Province is defined by complex geological features, including numerous faults and well-developed deep fractures. Soft rock strata account for more than $60 \%$ of the total thickness of the coal measure strata. Over the past ten years, due to gradually increasing mining intensity and the rapid downward extension of mining depth, new mines have reached 700-800 $\mathrm{m}$ deep, with some mines extending to $900-1000 \mathrm{~m}$. Most of the coal mines are highly gassy mines. Based on the development of technology for the simultaneous extraction of coal and gas, gobside entry retaining has been widely applied in these deep highly gassy mines [1]. However, support is relatively difficult to implement for gob-side entry retaining in deep mines, with strong rock pressure. After long-term practice, a set of new concepts has been formed for the application of deep gob-side entry retaining in the Huainan Mining Area [2], namely, 
"gob-side entry retaining implemented by stages-expanding and repairing foot slope-multiplexing." This method has been applied to Zhuji Mine (900 $\mathrm{m}$ deep), Dingji Mine (850 m deep), Panyi Mine (800 $\mathrm{m}$ deep), and Guqiao Mine (780 m deep). However, in terms of gob-side entry retaining, in the premining process, postmining in the working face, and intense mining in the adjacent advanced working face, especially for backstopping in this working face, numerous roof bed separations form on the retained entry, which are crushed and suffer severe deformation and failure, making forming a bearing structure difficult. As a result, in the process of expanding and repairing the coal side and floor with gob-side entry retaining and backstopping in the next working face, the surrounding rock suffers failure and instability, and caving may occur, seriously affecting the safety of the working face. In the field, measures such as using denser and longer bolts (anchor cables) are used as reinforcement but fail to effectively prevent large deformation of the surrounding rock, requiring a significant amount of repair work. Through underground investigation, field investigation, and analysis, experts reached an agreement that implementing gob-side entry retaining under a soft thick rock layer in deep mines with high stress is an engineering difficulty in the field of roadway support. Conducting systematic research on rock pressure behavior characteristics and control technology under such conditions is of great practical guiding significance for the popularization and application of gob-side entry retaining in deep mines.

Scholars in China and other countries have conducted significant research on surrounding rock-support theory in gob-side entry retaining. Zhang et al. [3] proposed a structural control principle regarding gob-side entry retaining for integral reinforcement based on the stiffness matching principle of a roadside supporting system. Zhang et al. [4] studied the activity laws of overlying strata in reinforced soil backfill mining and revealed the action mechanism of the roadside support body in gob-side entry retaining. Li et al. [5] established a numerical simulation model for overlying strata in gob-side entry retaining and clarified the influence laws of the rupture position of roof strata on crack expansion within the filling body. Chen et al. [6] conducted an in-depth study on the distribution relationships between entry-in support and the stress-displacement field of surrounding rock and illustrated the action mechanisms of entry-in and roadside support bodies. Han et al. [7] put forward the concept of a roadside composite bearing structure in gob-side entry retaining with greater mining height and revealed the control principle of roadside structure stability. Wu et al. [8] discussed and analyzed the geometrical morphology, severity, and dynamic evolution process of rock pressure behavior of surrounding rock in deep entry retaining and illustrated the asymmetric deformation and failure mechanisms of surrounding rock in deep gob-side entry retaining. Regarding the exploration and development of gob-side entry retaining support technology, He et al. [9] and Tan et al. [10] proposed an automatic roadway forming technology (110 construction method) through roof cutting and pressure relief and a support technology using the filling body in soft and hard composite layers, respectively. Masonry walls with cast-in- place concrete partition walls were primarily used for roadside support [11-13]. In terms of support materials, in recent years, the proposed concept of a support structure composed of prestressed bolts and anchor cables as well as innovations in its supporting essence has further developed the support technology, forming a high-prestressed and strong support system [14-16]. It makes the bolt and anchor cable still maintain higher support strength under high stress and strong mining conditions. A bolt with a constant-resistance and large deformation and anchor cable with negative Poisson's ratio have been researched and developed, with remarkable achievements in large-deformation roadway and rock-burst prevention. Grouting is also an important way to reinforce a fractured coal-rock mass [17-19]. Hollow grouting anchor cables have been developed, which can achieve full-length anchoring, deep-andshallow bore grouting, and integration of bolt and grouting [20]. Also, the anchor cables can effectively solve the problem of rapid attenuation and even loss of anchoring force caused by surrounding rock fractures in the dynamic pressurized roadway. It is suitable for complex engineering geological conditions such as high ground stress, soft and crushed rock mass, and large deformation [21, 22]. However, for the control of thick and soft surrounding rock with gobside entry retaining in deep mines, bolts (anchor cable), shed supports, and multiple renovations are generally used to maintain production in China and other countries, resulting in a sharp increase in support costs and roadway maintenance. In this paper, the lithologic characteristics of thick and soft surrounding rock with gob-side entry retaining in deep mines are examined; then, the deformation and failure forms of this kind of thick and soft surrounding rock are summarized and classified in order to analyze the causes of deformation and failure. On this basis, the control technology of thick and soft surrounding rock with gob-side entry retaining in deep mines is proposed. The results of this study are applied to the gob-side entry retaining project by Huainan Mining Group. Through long-term rock pressure observations, the surrounding rock has better support effects, satisfying the safety requirements for producing coal mines.

\section{Characteristics of Thick-Soft Mudstone in Huainan Mining Area}

2.1. Lithological Characteristics. The coal measure strata in the Huainan Mining Area are primarily composed of thick mudstone and sandy mudstone. A quantitative analysis was conducted on the calibrated mineral composition in the rock microstructure using the diffraction effect of X-ray in crystalline materials. Figure 1 shows the X-ray diffraction map of rock samples, and Table 1 shows the mineral composition of rock samples. The clay mineral content in the sandy mudstone reaches $51.46 \%$, and that in mudstone is as high as $67.31 \%$. According to the grading standard of expansive soft rock proposed by Pan et al. [23], sandy mudstone and mudstone are both determined to be medium expansive soft rock. 


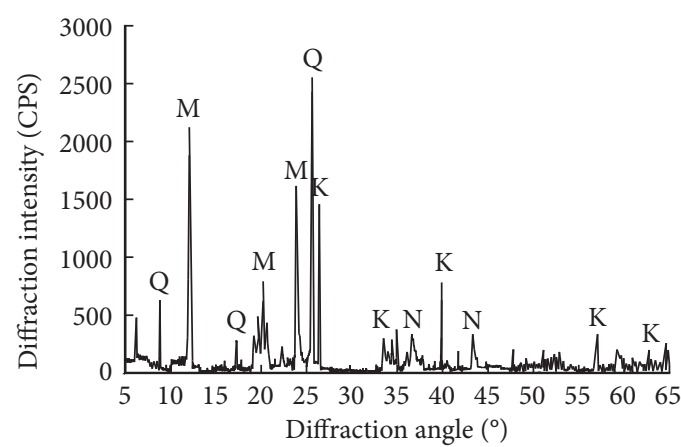

N-Nontronite

M-Illite

K-Kaolinite

Q-Quartz

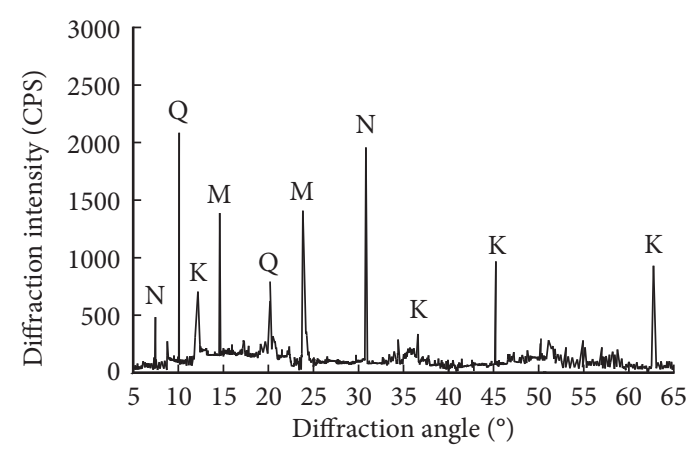

N-Nontronite

M-Illite

K-Kaolinite

Q-Quartz

(a)

(b)

Figure 1: X-ray diffraction diagram of rock samples. (a) Sandy Mudstone and (b) mudstone.

TABLE 1: The proportion of mineral components in rocks.

\begin{tabular}{lcccccc}
\hline Lithology & Nontronite/\% & Illite/\% & Kaolinite/\% & Quartz/\% & Montmorillonite/\% & Other minerals/\% \\
\hline Sandy mudstone & 8.93 & 19.32 & 20.24 & 31.70 & 11.90 & 7.91 \\
Mudstone & 4.69 & 21.68 & 27.20 & 23.30 & 18.43 & 4.70 \\
\hline
\end{tabular}

Better-cemented rock commonly requires more than two cycles. It is stipulated to use the disintegration index in the second cycle to denote index of rock disintegration resistance, as shown in Table 2. After the disintegration process with four cycles of water saturation-air drying, the rock sample is completely disintegrated, with the disintegration process of sandy mudstone and mudstone (Figure 2). The main structure of sandy mudstone and mudstone undergoes expansion and disintegration due to argillization after immersion, which greatly reduces rock strength.

Figure 3(a) shows the electron microscopic photo for the microstructure of sandy mudstone. The primary components of sandy mudstone are clay minerals, followed by quartz, muscovite, and a small amount of feldspar. Among them, the clay mineral content is relatively high, with particles clustered into blocks and crisscrossing in the form of flocculence. The clay mineral particles contain a large amount of irregular fine and laminar nontronite, fan-shaped laminated slab-like kaolinite, and filamentous illite, which are disorderly stacked with each other. These mineral particles are in the form of irregular flakes, with different sizes and irregular distribution. Each structural unit exists primarily in the form of agglomerates and laminations. The structural units and agglomerates are disorderly stacked with each other, forming a large number of $1-3 \mu \mathrm{m}$ micropores, indicating that micropores in the sandy mudstone are more developed.

Figure 3(b) shows the electron microscopic photo for the microstructure of mudstone. The clay content is greater in mudstone, and its primary components are kaolinite, hydromica, and montmorillonite. The morphology and structure of clay mineral particles in mudstone are similar to those in sandy mudstone, but the mudstone is primarily composed of fine particles with a particle size less than $0.0039 \mathrm{~mm}$, with smaller micropores between structural units. The clay mineral particles constitute the primary component of the mudstone, whose properties directly affect the water-weakening degree of mudstone.

\section{Analysis of Deformation and Failure Types of Thick and Soft Surrounding Rock}

Through field research and summary of gob-side entry retaining in deep mines such as Zhuji Mine (900 $\mathrm{m}$ deep), Dingji Mine (850 $\mathrm{m}$ deep), Panyi Mine (800 $\mathrm{m}$ deep), and Guqiao Mine (780 m deep), the deformation and failure characteristics of thick and soft surrounding rock in gobside entry retaining in deep mines are divided into eight types (Figure 4).

The roof bending and sinking type refers to a weak roof support structure with numerous bed separation areas, with increasing deformation and bed separation resulting in a significant increase in roof bed separation in the roadway, leading to roof bending and sinking (Figure 4(a)). For roof cutting along the filling body, no integral structure is formed in the roof above the filling area and the roof in the roadway, which leads to roof cutting in the roadway along the inner side of the filling body (Figure 4(b)). Rib spalling type refers to a bolt (anchor cable) supported body in the integrated coal side which has difficulty in effectively resisting the continuous deformation of the coal body into the roadway, and the middle and upper part of the coal side loosely expand and deform forming a range of rib spalling, thus losing the effective support of the roof (Figure 4(c)). The large-span roof fall type refers to roofs over the retained roadway with a larger span, and the roof strata (especially the shallow strata) bear 
TABLe 2: Index of rock disintegration resistance.

\begin{tabular}{lcccccc}
\hline \multirow{2}{*}{ Specimen number } & \multirow{2}{*}{ Rock name } & \multicolumn{3}{c}{ Disintegration resistance index } & \multirow{2}{*}{ Disintegration resistance classification } \\
& & Cycle 1 & Cycle 2 & Cycle 3 & Cycle 4 & Medium \\
1 & Sandy mudstone & 94.1 & 88.3 & 79.2 & 72.6 & Medium \\
\hline
\end{tabular}
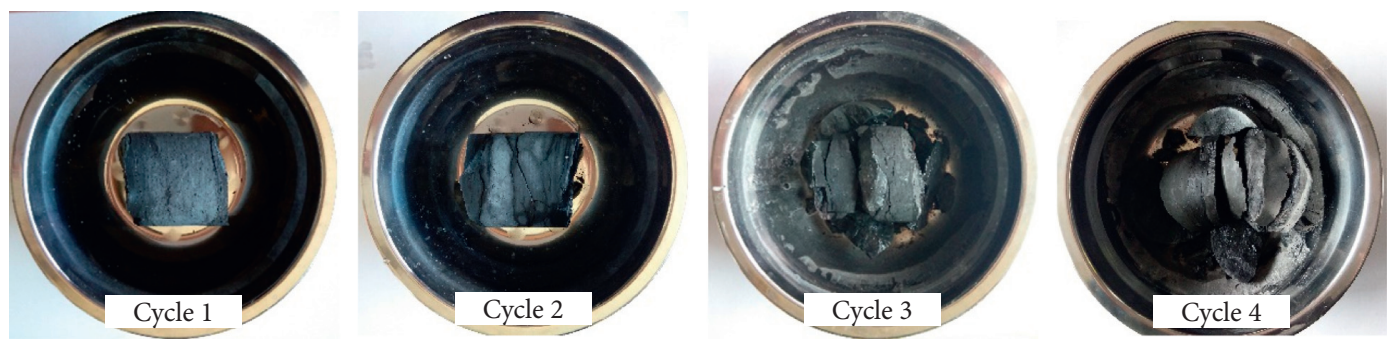

(a)
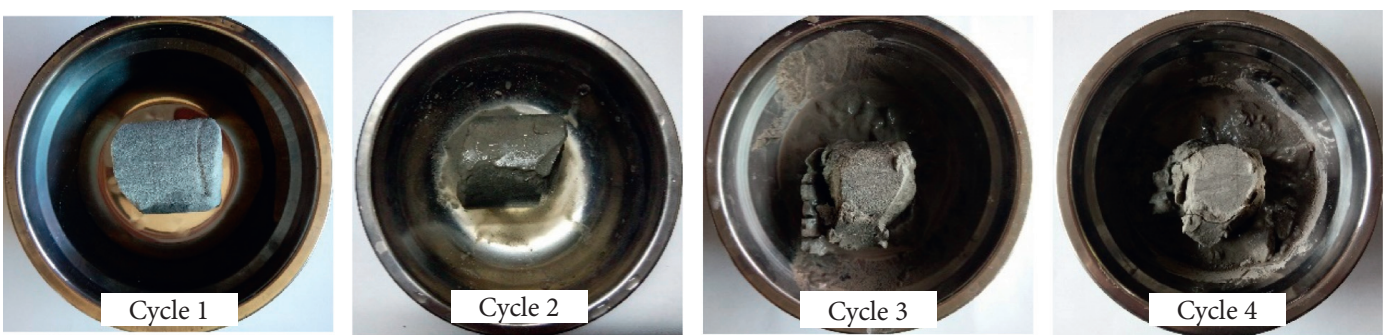

(b)

FiguRE 2: Disintegration resistance test of rock samples. (a) Disintegration process of mudstone and (b) disintegration process of sandy mudstone.

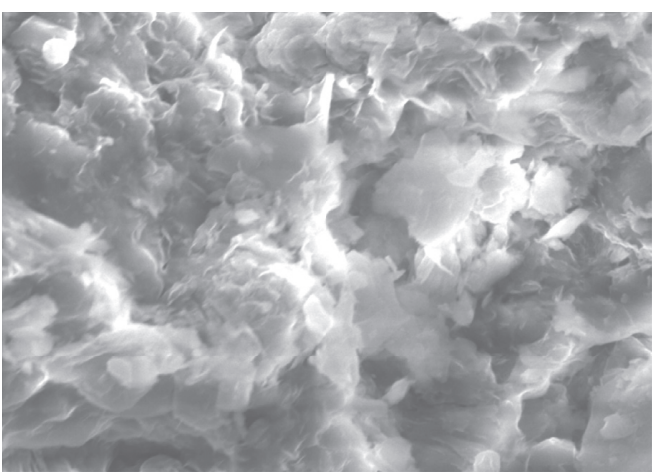

(a)

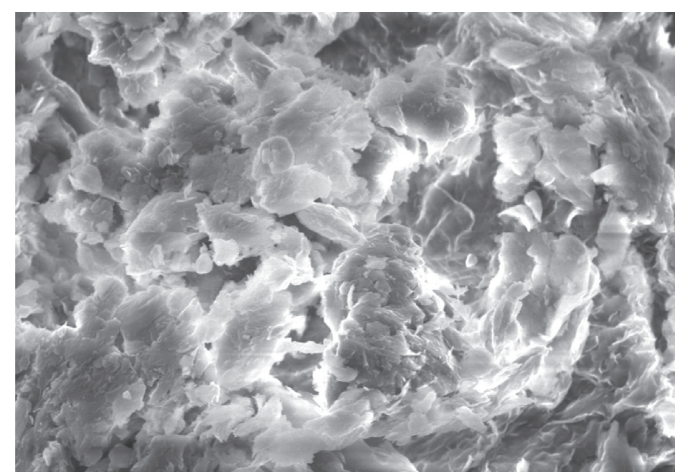

(b)

Figure 3: SEM images of rock samples. (a) 5000 times sandy mudstone picture and (b) 5000 times mudstone pictures.

higher tensile stress and have a strong sensitivity to disturbance, showing a state of larger-scale fragmentation, resulting in rapid sinking and even collapse (Figure 4(d)). Filling body rotation refers to when the filling body rotates with the inclination of the roof during violent activity in the overlying strata in the gob-side entry retaining (Figure 4(e)). Filling body crushing refers to when the support resistance of the filling body beside the roadway is lower at the initial stage of the retained roadway, the pressure of overlying strata exceeds its utmost bearing capacity, and the filling body is crushed, causing the roof to incline and sink sharply (Figure 4(f)). Roof step type refers to when steps are formed and gradually increase between the original roof and the newly exposed roof in the process of expanding and repairing the cross-section in gob-side entry retaining (Figure $4(\mathrm{~g})$ ). If not handled in time, the "steps" in the roof will expand, causing separation of the roof or even collapse. Roof cutting along the coal side refers to when there is a certain distance away from the front of the working face, and the roof is cut along the coal side and sinks as a whole (Figure $4(\mathrm{~h})$ ). Coal side roof cutting during the reuse of a gob-side entry retaining, with intense activity in the overlying strata. 


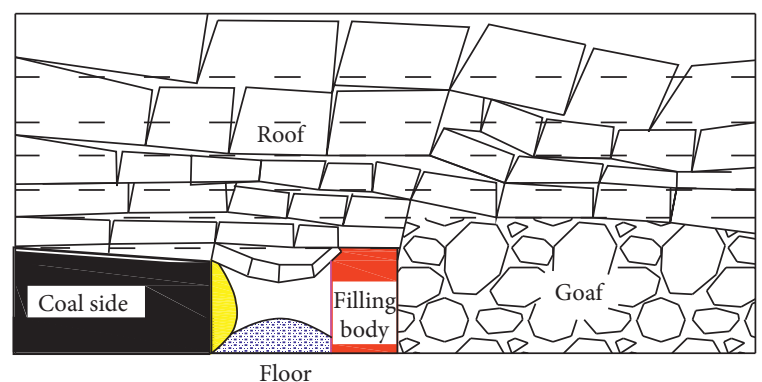

(a)

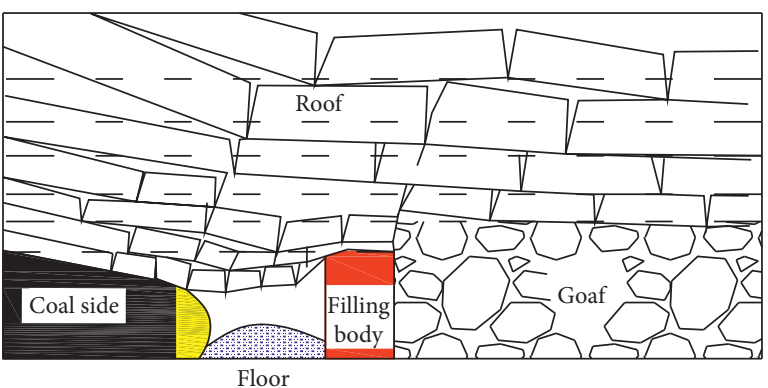

(c)

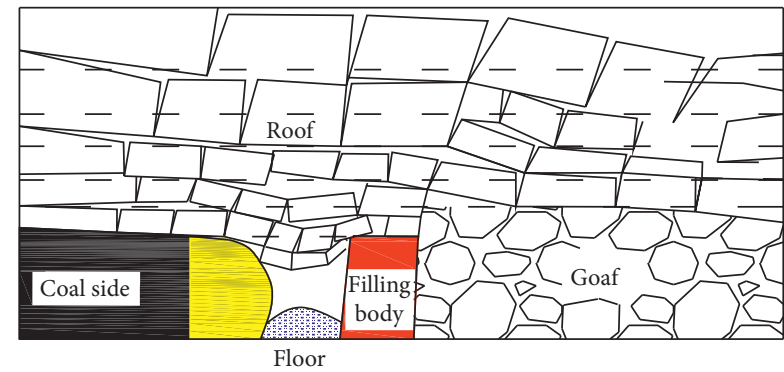

(e)

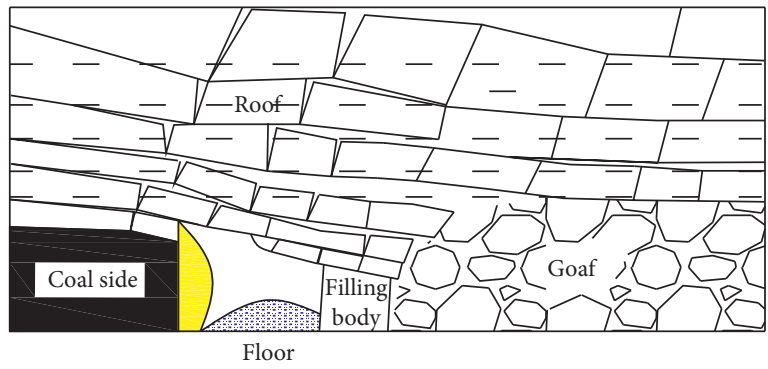

(g)

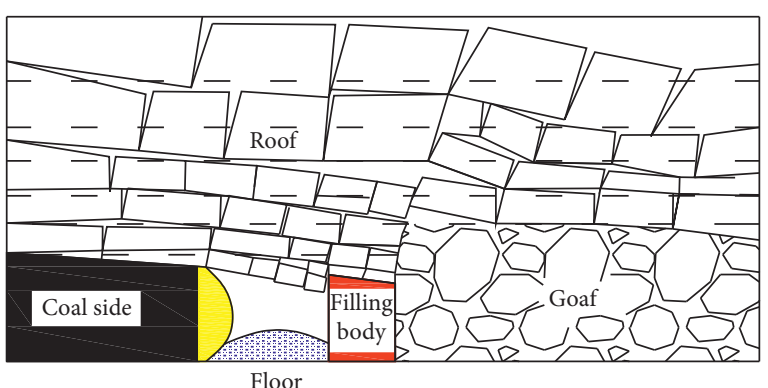

(b)

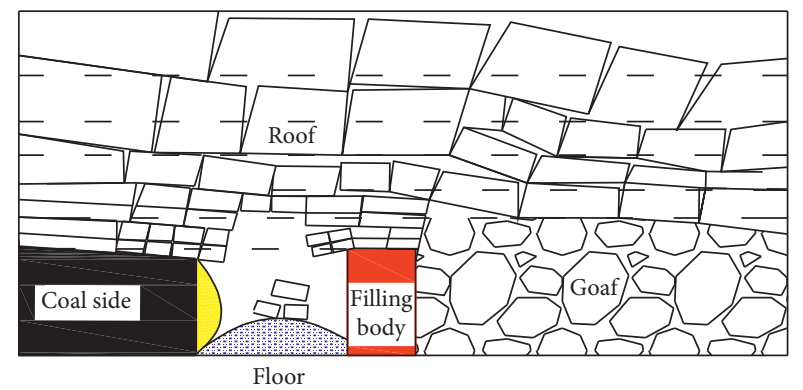

(d)

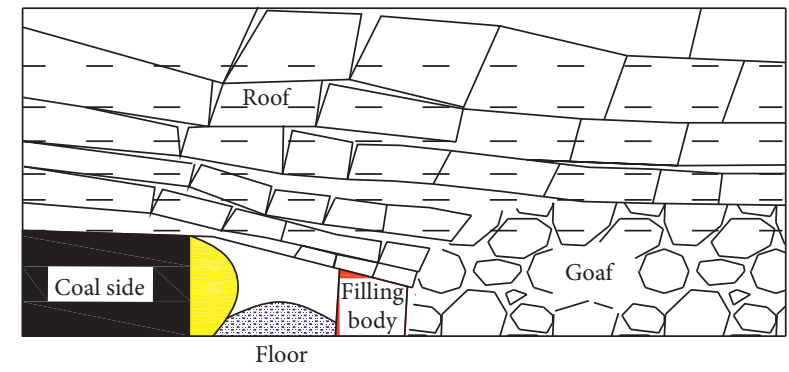

(f)

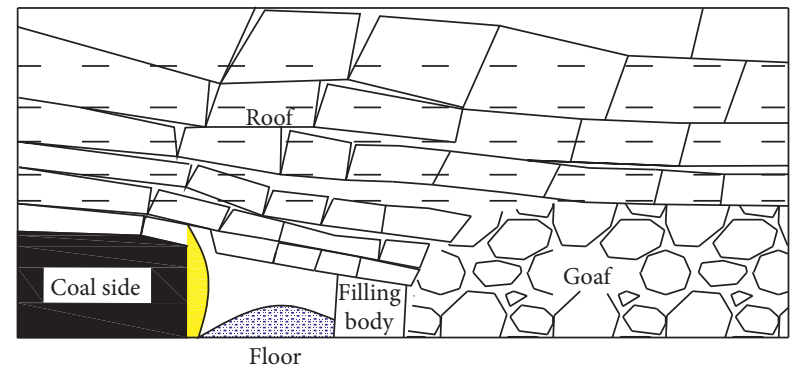

(h)

FIGURE 4: Deformation and failure characteristics of surrounding rock. (a) Roof bending and sinking type, (b) roof cutting along filling body, (c) rib spalling type, (d) roof fall type, (e) filling body rotation type, (f) filling body crushing type, (g) roof step type, and (h) roof cutting along coal side.

According to laboratory testing analysis and engineering field results, it is believed that the large deformation of thick and soft surrounding rock in gob-side entry retaining in deep mines primarily originates from two aspects, namely, the natural condition of coal-bearing rock strata and man-made control factors. When the former is determined, the latter plays a driving role. From the surrounding rock deformation and failure types, the support type and support strength of surrounding rock structure in gob-side entry retaining cannot achieve coupling, and no complete bearing body is formed in the support system and the bolt (anchor cable) in the area with the stress concentration breaks and the coal-rock mass fractures, further causing the support systems to be successively crushed. In addition, the gob-side entry retaining is in the thick sandy mudstone and mudstone, and creep displacement of surrounding rock is not affected by the relevant constraints. The long-term creep speed will not decrease but will accelerate with the expansion of loosened rock circles 
around the surrounding rock, which makes roadway maintenance more difficult.

\section{Measures for Zonal and Grading Control of Thick and Soft Surrounding Rock}

The stability of surrounding rock in gob-side entry retaining not only depends on the roof stability but also is closely related to the two sides and floor. Therefore, effectively controlling the roof deformation in the retained roadway and strengthening the support for the side sections and floor are necessary. Based on the dynamic response characteristics of thick and soft surrounding rock migration and failure and the initial point and key point for chain reaction of support structure deformation and failure in gob-side entry retaining of deep mines in the Huainan Mining Area, the thick and soft surrounding rock support in the gob-side entry retaining is graded and zoned (Figure 5).

The roof, floor, and two sides can be divided into four levels based on the difficulty of the support of each part of the surrounding rock in the gob-side entry retaining. Among them, the roof in gob-side entry retaining is divided into Zone I, Zone II, and Zone III, belonging to the first-level support area; the roadside filling area is divided into Zone IV, Zone V, and Zone VI, belonging to the second-level support area; the solid coal side is divided into Zone VII and Zone VIII, belonging to the third-level support area; Zone IX on the floor and Zone $X$ in the roadway belong to the fourthlevel support area. On this basis, the key technology of "grading and zoning and overall reinforcement" for thick and soft surrounding rock in gob-side entry retaining in deep mines is further proposed.

4.1. Analysis of Coupling Support in Three Zones on the Roof. The roof in gob-side entry retaining is roughly divided into three zones for control, namely, the roof in the filling area (Zone I), the roof in the roadway (Zone II), and the roof on the solid coal side (Zone III). Further analysis is conducted on the role of each zone on the roof and the coupling support mode as follows.

4.1.1. Roles of the Roof in the Filling Area. The bearing capacity of the roof in the filling area beside the roadway has an important influence on the surrounding rock stability in gob-side entry retaining [24]. The roof in the filling area beside the roadway is located at the extreme edge of the goaf. During violent activity in the overlying rock in the goaf, the roof strata in this area move violently and the stress concentration increases. If the roof strata are fractured and the fracture development is extremely unstable, the roof will lose the effective point of force on the side near the goaf, causing the filling body to not fully play its supporting role, leading to a large area of roof inclination and sinking. Generally, there are two types of failure modes for thick-soft roof in the filling area, namely, loose fractured roof and rheoextrusion roof (Figure 6).

Loose fractured roof refers to when the roof in filling area undergoes fracturing, rib spalling, or collapse under

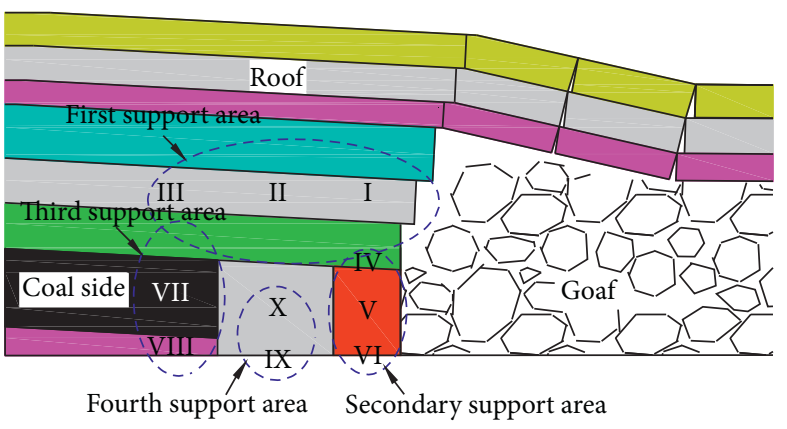

FIGURE 5: Support zone of thick-soft surrounding rock of deep gobside entry retaining. I: the roof in filling area; II: the roof in roadway; III: the roof above solid coal side; IV: the zenith zone of filling body; V: the filling body; VI: the bottoming zone of filling body; VII: the middle and upper area of solid coal side; VIII: the lower area of solid coal side; IX: floor; X: roadway.

increased stress or mining activity, and the fractured rock mass pours into the goaf, causing the roof in this area to be in a suspended state; therefore, the filling body cannot fully support the roof. Rheoextrusion roof refers to when a thick low-strength incompetent bed is subjected to rheoextrusion in a high-stress state, making the filling body cut into the roof and causing the roof structure to fail and sink. Under two roof conditions, it is also difficult to give full play to the bearing capacity of the filling body.

4.1.2. Roles of the Roof in the Roadway. Maintaining the stability of the roof in the roadway is key to preventing roof collapse and leakage, which are also requirements for safe roadway use. According to field research, the roof bed separation bending and sinking type and the type of largespan roof fall primarily result from a low roof support strength. Roof cutting along the filling body and roof cutting along the coal side are primarily caused by uncoordinated support of the three roof zones.

4.1.3. Role of the Roof on the Solid Coal Side. The roof on the solid coal side is also an important part of the roof in the retained roadway that belongs to the fixed end of cantilever beam in the goaf. After this area is affected by strong mining, fractures develop within the roof strata, which inclines to one side of the goaf and sinks. The secure anchor cable on the coal side of the roof loosens, causing the roof to become extremely unstable (Figure 7).

Keeping the roof intact is the key to the success of gobside entry retaining. To achieve optimal support, making an overall plan for the coupling support of the three zones of the roof is necessary. The steps for the coupling support of the three zones of the roof are as follows: first, cable-stayed anchor cables are arranged on both sides of Zone II on the roof, and both ends of the anchor cables are installed securely with no crack, namely, Zone I and Zone III on the roof, so as to improve the support strength of the roof at the shoulder corner of the roadway and prevent the roof from breaking and sinking along the two-side angles during roadway retaining; second, grouting is performed in Zone II 


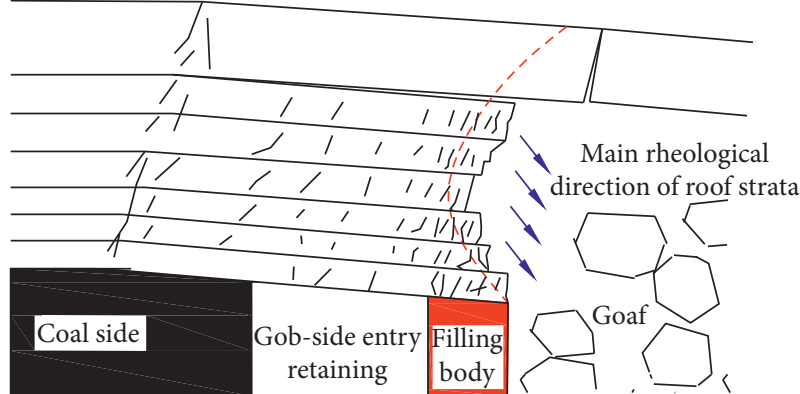

(a)

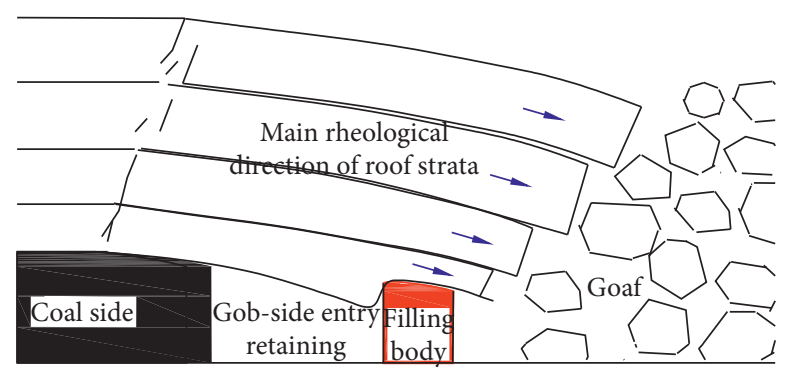

(b)

FIgURE 6: Failure types of the roof in the filling area. (a) Loose fractured roof and (b) rheoextrusion roof.

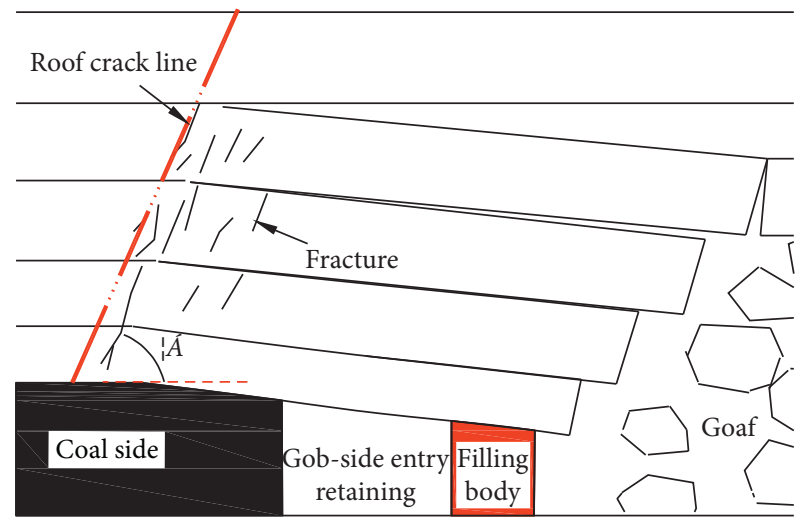

FIGURE 7: Fracture development area of the roof above the solid coal side.

of the roof in the roadway at a certain distance from the advanced working face to reinforce the fractures and cataclastic rock strata within the roof, in order to improve the mechanical properties and self-supporting capacity of the coal-rock mass, provide a reliable foundation for force application of the anchor bolt (cable), improve the stress state, and ensure the reliability of the anchor bolt (cable); third, the anchor bolt (cable) is used for strengthening the roof with a notch at the end of the working face (Zone I) to prevent roof collapse in the filling area, providing good conditions for smoothly implementing roadside filling. Finally, the roof is fixed together via the coupling support of three zones on the roof in order to restrain discontinuous deformation such as roof bed separation, dislocation, crack opening, and new crack development as well as to ensure the roof is smooth.

4.2. Analysis of the Collaborative Control of the Two Zones on the Coal Side. Strengthening the support structure of the side of the coal-rock mass plays an important role in guaranteeing roof stability in gob-side entry retaining, which can not only improve the roof bearing capacity but also restrain floor heave. In the Huainan Mining Area, most coal seams have medium thickness. The full-coal side and halfcoal-rock side may appear in the side part. Based on the location, the side part can be divided into the upper side area and the lower side area.
4.2.1. Upper Side Area. The high lateral abutment pressure and insufficient support strength in the mining stope are the primary reasons for deformation and failure of the solid coal side. Different coal seam conditions, including hardness, development of joint fissures, and geological structure development, lead to varying coal side failure types. Relatively speaking, the coal side in soft coal seams suffers more frequent and serious failure, and the upper part of the coal body on the coal side is loose and fractured, with outward bulge, spalling, and even rib spalling, which weakens the roof bearing capacity.

4.2.2. Lower Side Area. High abutment pressure, insufficient support strength, and fissure water erosion are the primary reasons for deformation and failure of the mudstone layer in the lower side area. The primary failure mode is defined by large deformation and large convergence, resulting in a larger range, higher damage degree of bulge, and outwardbulge rib spalling in the upper side area.

Through analysis of the side support, in the process of gob-side entry retaining, the high abutment pressure on the roof transfers and concentrates in the deep part of the coal side, resulting in a significant extension of the fracture zone, plastic zone, and elastic zone successively from the outside in. In terms of supporting on the coal side, due to an insufficient anchor bolt length, the whole anchoring body is commonly displaced, and serious outward bulging and rib spalling occur. Therefore, the paper focuses on discussing parameters such as the equilibrium zone width on the solid coal side, the support strength of the anchor bolt (cable), and the distribution and length of elastic-plastic zones (Figure 8).

4.2.3. Limit Equilibrium Zone on the Solid Coal Side. The fracture zone, plastic zone, zone with increasing elastic stress, and zone with the primary rock stress are formed successively from the outside in on the solid coal side (Figure 8). The formula for calculating the equilibrium zone width $\mathrm{x} 0$ is as follows [25]:

$$
x_{0}=\frac{M A}{2 \tan \varphi_{0}} \cdot \ln \left(\frac{k \gamma H+\left(c_{0} / \tan \varphi_{0}\right)}{\left(c_{0} / \tan \varphi_{0}\right)+\left(p_{x} / A\right)}\right),
$$

where $M$ denotes mining height and the unit is $m$; $A$ denotes the coefficient of lateral pressure; $H$ denotes mining depth 


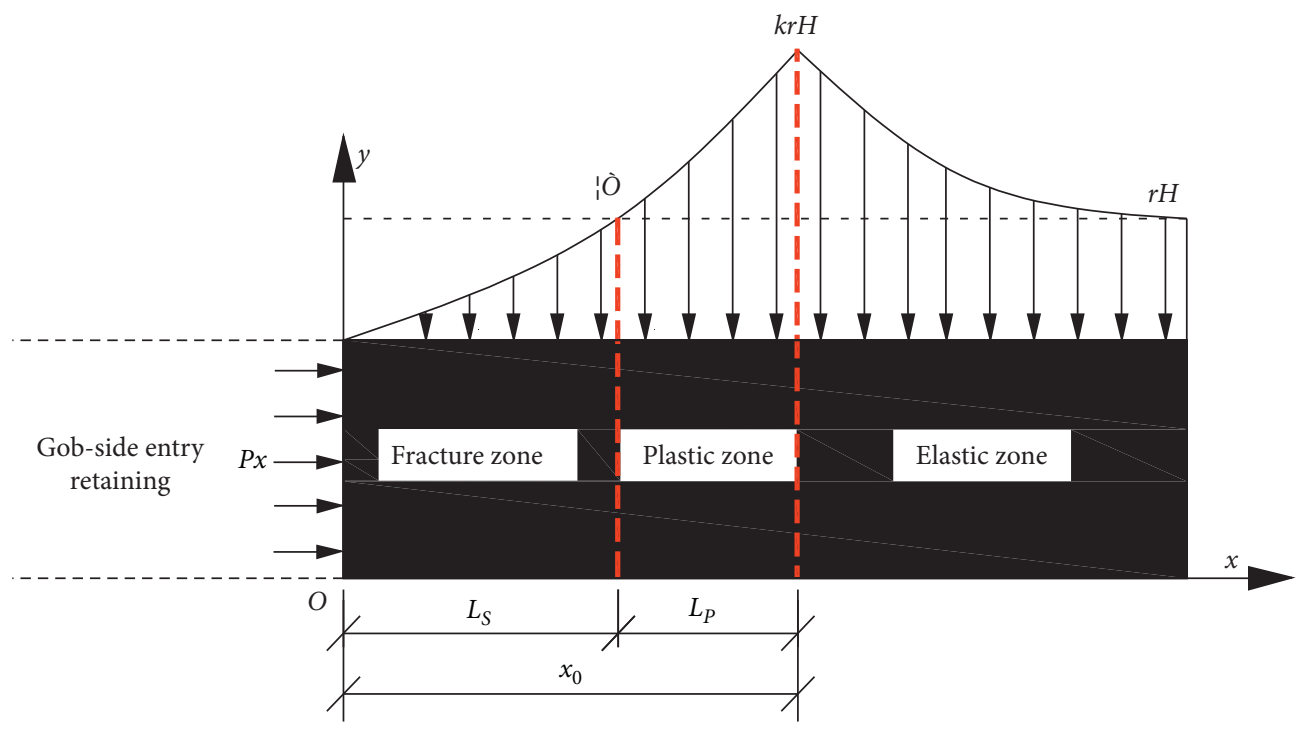

FIGURE 8: Analysis model of fracture zone and plastic zone in solid coal side.

and the unit is $m$; $c_{0}$ denotes the cohesion of the coal-rock strata interface and the unit is $\mathrm{MPa} ; \varphi_{0}$ denotes the internal friction angle of the coal-rock strata interface and the unit is $\left({ }^{\circ}\right) ; P_{x}$ is the support strength of the solid coal side and the unit is $\mathrm{MPa} ; k$ denotes the maximum stress concentration factor; and $\gamma$ denotes the average volume weight of overlying strata and the unit is $\mathrm{kN} / \mathrm{m}^{3}$.

Relevant parameters are set as follows: $H=810 \mathrm{~m}$, $M=2.5 \mathrm{~m}, A=0.4, k=3, \varphi_{0}=36^{\circ}, \gamma=24 \mathrm{kN} / \mathrm{m}^{3}, c_{0}=0.3 \mathrm{MPa}$, and $P_{x}=0.24 \mathrm{MPa}$, and the variation curve for the width of the limit equilibrium zone is shown in Figure 9. With increasing mining depth $H$, the equilibrium zone width $x_{0}$ shows an increasing trend. When the support strength $P_{x}$ and the cohesion of coal-rock strata interface $c_{0}$ change, the equilibrium zone width $x_{0}$ increases rapidly. With the mining depth $H$ being constant, when the support strength $P_{x}=0.1 \mathrm{MPa} \longrightarrow 0.5 \mathrm{MPa}$, the width of the limit equilibrium zone $x_{0}=1.8 \mathrm{~m} \longrightarrow 1.0 \mathrm{~m}$, showing a gradually decreasing trend; when the mining height $M=1 \mathrm{~m} \longrightarrow 5 \mathrm{~m}$, the width of the limit equilibrium zone $x_{0}=0.4 \mathrm{~m} \longrightarrow 3.0 \mathrm{~m}$, showing a gently increasing trend; when the coefficient of lateral pressure $A=0.1 \longrightarrow 0.5$, the width of the limit equilibrium zone $x_{0}=1.1 \mathrm{~m} \longrightarrow 1.9 \mathrm{~m}$, showing a gently increasing trend in an approximately linear manner; when the stress concentration factor $k=2 \longrightarrow 10$, the width of the limit equilibrium zone $x_{0}=1.1 \mathrm{~m} \longrightarrow 1.9 \mathrm{~m}$, showing a slowly rising trend; when the cohesion of coal-rock strata interface $c_{0}=0.11 \longrightarrow 0.5$, the equilibrium zone width $x_{0}=1.6 \mathrm{~m} \longrightarrow 1.0 \mathrm{~m}$, showing a rapidly decreasing trend; when the internal friction angle of coal-rock strata interface $\varphi_{0}=10^{\circ} \longrightarrow 50^{\circ}$, the equilibrium zone width $x_{0}=0.2 \mathrm{~m} \longrightarrow 2.7 \mathrm{~m}$, showing a gently increasing trend. Thus, with increasing mining height $M$, lateral pressure coefficient $A$, stress concentration factor $k$, and internal friction angle of coal-rock strata interface $\varphi_{0}$, the equilibrium zone width shows an increasing trend; with increasing support strength $P_{x}$ and cohesion of the coal-rock strata interface $c_{0}$, the equilibrium zone width shows a decreasing trend.
According to the actual mining conditions in the working face, making $H, K, \gamma$, and $A$ constant is the most direct and effective way to increase the support strength $P_{x}$ or increasing the coal-rock strata interface parameters $c_{0}$ and $\varphi_{0}$.

4.2.4. Length of Anchor Bolt (Cable) on the Solid Coal Side. To maintain the stability of the solid coal side, the length of the anchor bolt should be greater than the width of the fractured zone on the coal side, and the length of the anchor cable should be greater than the width of the limit equilibrium zone in order to avoid rid spalling on the coal side and displacement of the whole anchoring body. The length of the anchor bolt (cable) shall meet the following specific conditions:

$$
\begin{aligned}
L_{\text {bolt }} & =m+L_{s}+s_{1}, \\
L_{\text {anchorbolt }} & =n+x_{0}+s_{2},
\end{aligned}
$$

where $m$ is the exposed length of the anchor bolt, depending on the bolt type and the anchoring mode, for which the value is generally taken as $0.1-0.15 \mathrm{~m} ; s_{1}$ denotes the length of the anchor bolt anchored into the plastic zone, the anchoring length at the end is generally $0.3-0.4 \mathrm{~m}$, and $s_{1} \geq 0.4 \mathrm{~m} ; n$ denotes the exposed length of the anchor cable, the value for which is generally $0.25-0.35 \mathrm{~m}$; and $s_{2}$ is the depth of the anchor cable anchored into the elastic zone, for which the empirical value is not less than $1.5 \mathrm{~m}$.

4.3. Analysis of Composite Bearing of Three Zones beside the Roadway. The composite bearing of structures beside the roadway refers to integrating the filling body, roof joint area, and floor joint area together to form a composite bearing structure. The composite bearing methods for the three zones are analyzed in detail as follows. 


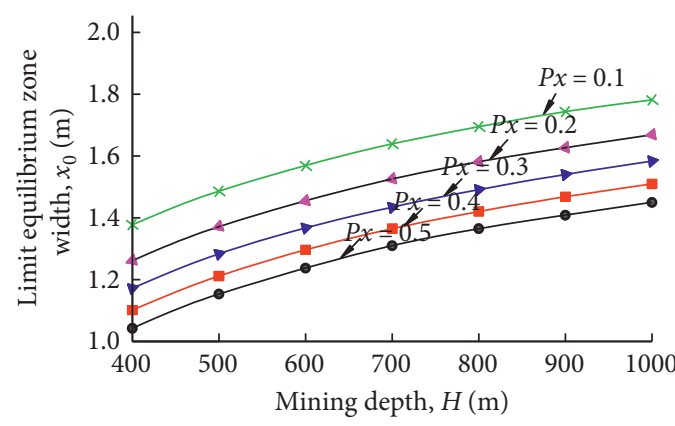

(a)

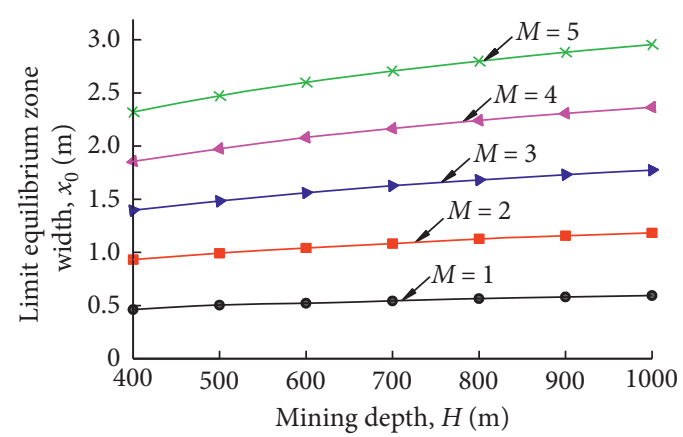

(c)

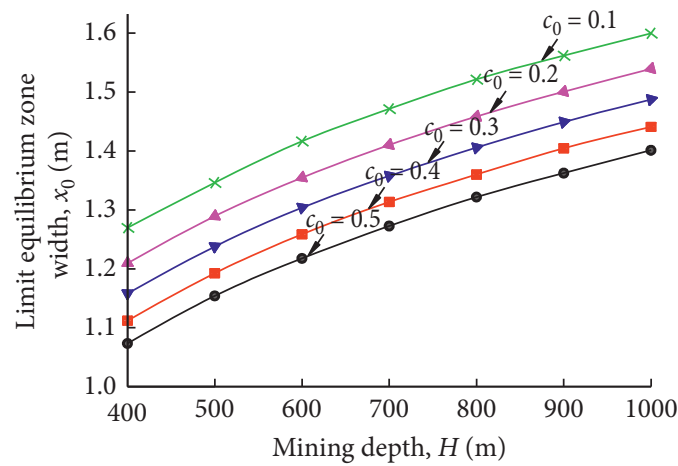

(e)

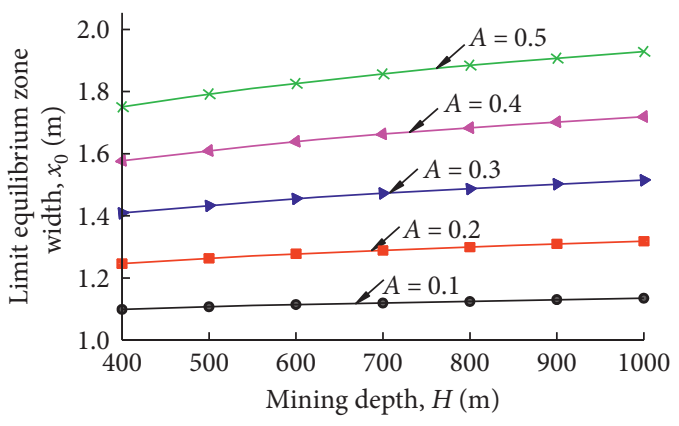

(b)

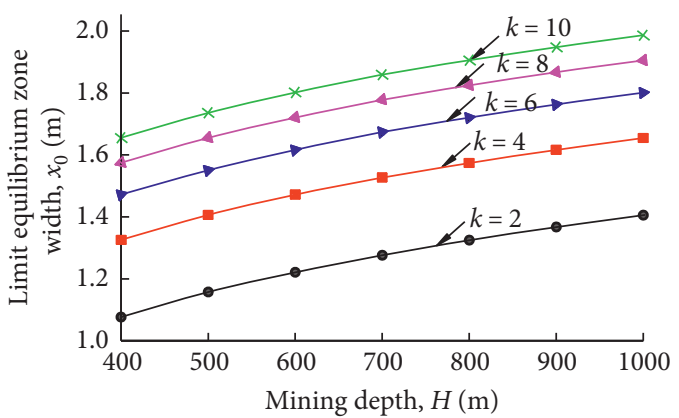

(d)

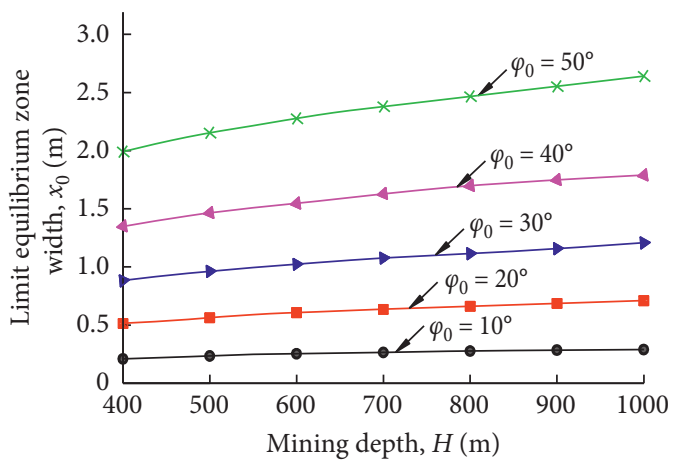

(f)

FIgURe 9: Variation curve of limit equilibrium zone width. (a) $x_{0}$ distribution curve with the change of support strength $P_{x}$, (b) $x_{0}$ distribution curve with the change of mining height $M$, (c) $x_{0}$ distribution curve with the change of lateral pressure coefficient $A$, (d) $x_{0}$ distribution curve with the change of maximum stress concentration factor $(k)$, (e) $x_{0}$ distribution curve with the change of coal-rock interface cohesion $c_{0}$, and (f) $x_{0}$ distribution curve with the change of internal friction angle of coal-rock interface $\varphi_{0}$.

4.3.1. Filling Body. The filling body represents the core composite bearing capacity of the structure body beside the roadway [26]. Its bearing capacity and deformation capacity should match the supporting mode and support strength of the roof and floor, so that the movement of the filling body and that of the roof and floor can be coordinated.

4.3.2. Roof Joint Area of Filling Body. The roof joint area is the link connecting the roof and the filling body within the filling area. The technical requirements of the roof joint area are as follows: (1) ensuring a smooth roof surface in the roof joint area; (2) connecting the internal reinforcement framework in the filling body to complete the integration; (3) filling and compacting the gap in the roof joint area to promote a uniform of the load-bearing capacity of the filling body. The steps to strengthen the roof support in the filling area are as follows: first, a notch is opened on the advanced stope side at the working face end; then, an anchor bolt (cable) is used to reinforce the roof with a notch in advance; finally, the smoothness of the roof is ensured so that the filling body can be fully connected to the roof and the bearing capacity is uniform.

4.3.3. Floor Joint Area of the Filling Body. The floor joint area of the filling body is the foundation for bearing the load from the upper structure, which should have enough bearing capacity to avoid overturning or instability in the substructure. The supporting methods for the filling area floor include (1) tamping the foundation bed of the filling body to increase the force area of its hit bottom; (2) connecting the 
prefabricated anchor bolt for the floor in the filling area with the reinforcement framework in the filling body to form a complete unit; (3) treating the water accumulation on the floor caused by the filling besides the roadway to prevent softening due to soaking.

4.4. Analysis of Auxiliary Support by Stages in the Roadway. Before the bearing capacity of the structure body beside the roadway has not been fully exerted and the filling body reaches the final set strength, the loads on each zone of the surrounding rock-supporting structure are all relatively large. An auxiliary strengthening support needs to be implemented in the roadway to assist with bearing the weight of the filling body, control roof sinking, and restrain floor heave, thus achieving double control of the roof and floor. The supporting technologies in the roadway primarily include (1) individual hydraulic prop $+\pi$-type steel girder + column shoes with high strength and large-size; (2) a special support used in the roadway.

The floor heave is common in gob-side entry retaining. Especially in gob-side entry retaining in deep mines, the rock pressure behavior is extremely strong, and floor heave is particularly serious. However, gob-side entry retaining is different from roadway exploration and preparation, which requires less time. Spending significant time on floor heave prevention and control is inadvisable. In addition, carrying out floor construction is inconvenient, the support reinforcement requires a large amount of work, and it is difficult to do repair; thus, no-support countermeasures are commonly taken for the floor.

\section{Industrial Test}

5.1. Engineering Geological Conditions. The test minefield is located in the northeast Huainan Coalfield, upper bend in Panji, and the south wing of hinge zone of the pitch in the east. In general, the minefield has a slightly asymmetric upper-bend structure. The axial tilt angle of upper bend is $1^{\circ}-9^{\circ}$; the strike length of the test working face is $1260 \mathrm{~m}$; the slope length is $245 \mathrm{~m}$; the burial depth is $810 \mathrm{~m}$; and the attitude of the coal-rock strata is $153^{\circ}-180^{\circ} \angle 6^{\circ}-9^{\circ}$, with a mean dip angle of $7^{\circ}$. The 11-2 coal seam is primarily mined in the working face: the coal seam is $0.9 \mathrm{~m}-4.0 \mathrm{~m}$ thick, with an average thickness of $2.3 \mathrm{~m}$, which is a medium-thickness coal seam. The coal seam structure is simple; part of the coal seam contains 1-3 layers of dirt bands, which are mostly composed of mudstone or carbonaceous mudstone. The roof of the coal seam is primarily composed of mudstone and sandy mudstone, while some parts are composed of sandstone and siltstone, and the floor is composed of mudstone and sandy mudstone, with sparse fine siltstone (Figure 10). The hydrogeological conditions in this area are relatively simple, but dangerous gas outbursts do occur. The original gas content in $11-2$ coal seam is $11.1 \mathrm{~m}^{3} / \mathrm{t}$.

In the test working face, gob-side entry retaining is used in the section track drift with a width $\times$ height of $5000 \mathrm{~mm} \times$ $3200 \mathrm{~mm}$. According to the relevant requirements in the simultaneous extraction of coal and gas with no coal pillars in

\begin{tabular}{|c|c|c|}
\hline Histogram & Stratum name & Thickness/m \\
\hline--- & Sandy mudstone & $0 \sim 4.2 / 2.2$ \\
\hline & Fine sandstone & $0 \sim 5.2 / 1.3$ \\
\hline \multirow{3}{*}{ 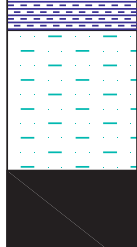 } & Mudstone & $0 \sim 2.0 / 1.1$ \\
\hline & Sandy mudstone & $0 \sim 7.4 / 3.1$ \\
\hline & Coal seam 11-2 & $0.9 \sim 4.0 / 2.3$ \\
\hline \multirow{3}{*}{ 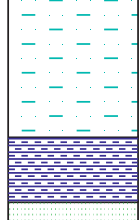 } & Sandy mudstone & $1.5 \sim 8.2 / 3.4$ \\
\hline & Mudstone & $0.3 \sim 2.6 / 1.5$ \\
\hline & Siltstone & $0 \sim 1.7 / 0.5$ \\
\hline
\end{tabular}

FIGURE 10: Histogram of coal-rock strata in the working face.

Huainan Mining Area, the section area after the retained roadway is stable shall not be less than $8 \mathrm{~m}^{2}$. The mode of half in situ gob-side entry retaining is adopted. The location of the filling body beside the roadway has a deviation of $\Delta h=800 \mathrm{~mm}$ towards the roadway; thus, the width $\times$ height of gob-side entry retaining is $4200 \mathrm{~mm} \times 3200 \mathrm{~mm}$. The designed section meets the requirements, with enough deformation allowance.

\subsection{Support Parameters and Control Effect on Each Zone of the} Surrounding Rock. According to the new grading and zoning support method for thick and soft surrounding rock in gobside entry retaining in deep mines, in combination with the research findings and accumulated practical experience form the Huainan Mining Area in thick and soft surrounding rock supported with gob-side entry retaining in deep mines, the thick and soft surrounding rock is zoned and the support scheme is designed. The specific supporting parameters of surrounding rock at each stage from drifting in the section track drift to gob-side entry retaining are shown in Figure 11.

5.2.1. Support Parameters of the Section Track Drift. Roof support: Zone II plays a dominating role, supplemented by Zone I and Zone III. The specific supporting parameters are as follows: six left-handed screw thread steel bolts without longitudinal reinforcement of $\Phi 22 \mathrm{~mm} \times L 2500 \mathrm{~mm}$ are installed in each row, equipped with M5 steel strip and metal netting. They are vertically arranged, with a row spacing of $900 \mathrm{~mm} \times 800 \mathrm{~mm}$ and preloaded to $60-80 \mathrm{kN}$. A group of anchor cables of $\Phi 22 \mathrm{~mm} \times L 7300 \mathrm{~mm}$, together with $14^{\#}$ channel steel, are arranged between the two rows of anchor bolts, which are laid out vertically according to the arrangement mode of " $3-3$ "; a hollow grouting anchor cable of $\Phi 22 \mathrm{~mm} \times L 7300 \mathrm{~mm}$ is arranged at each end of the channel steel, with them tied at an angle of $15^{\circ}$ outward; and it is anchored into the crack-free area deep in Zone I and Zone 


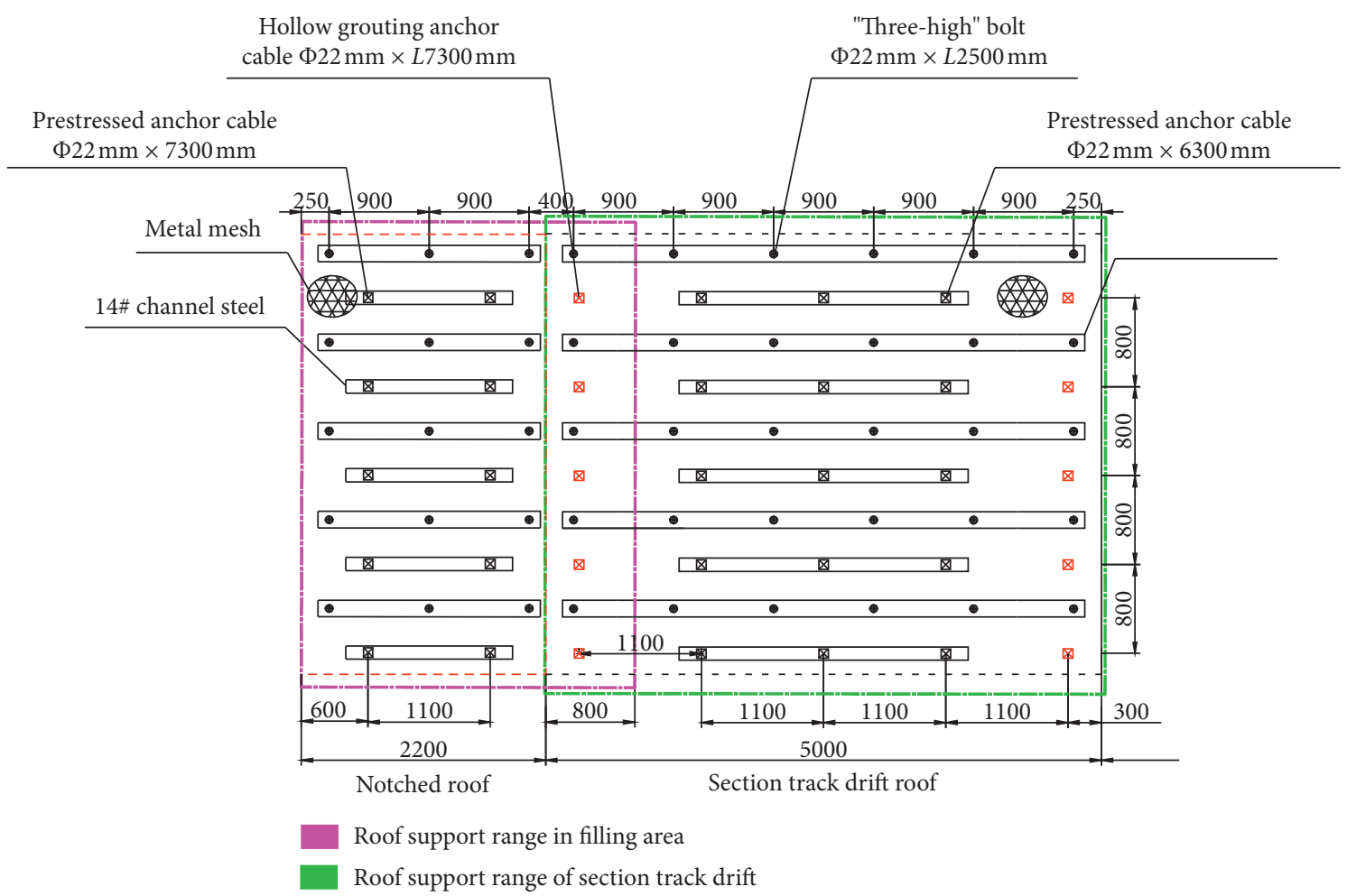

(a)

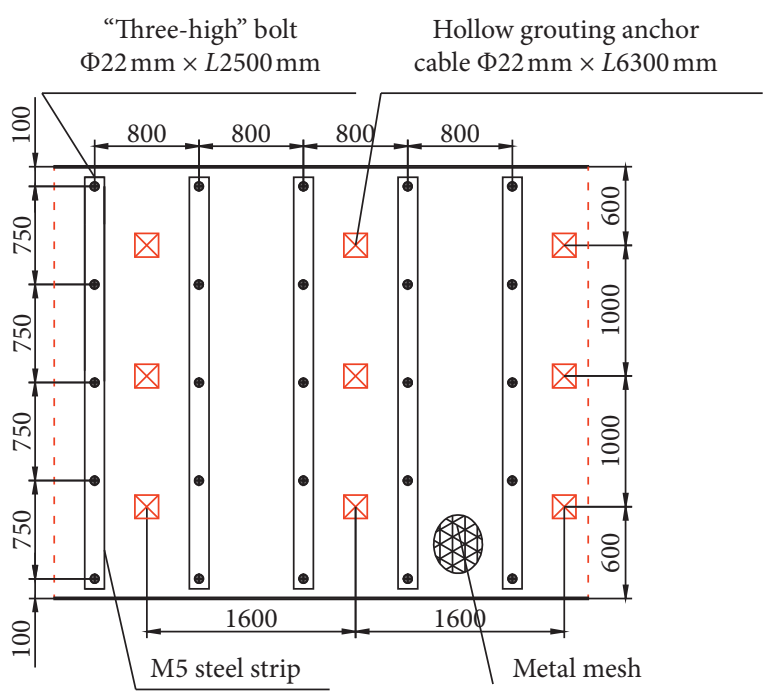

(b)

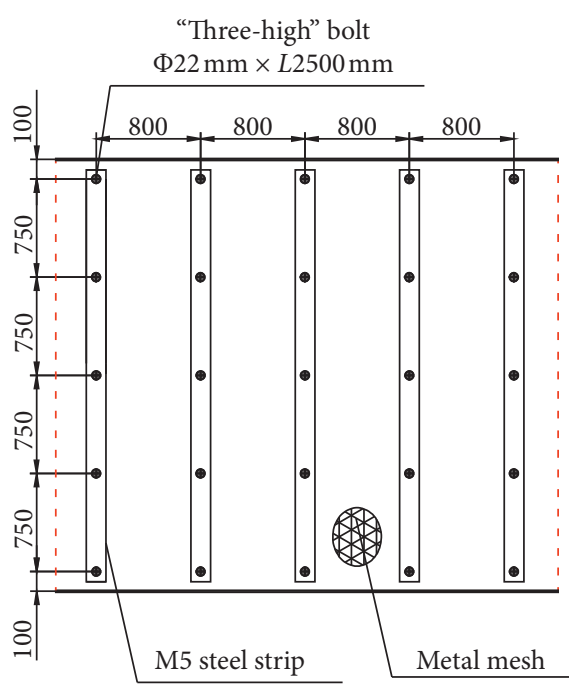

(c)

FIGURE 11: Support scheme of surrounding rock. (a) Support parameters of roadway roof, (b) support parameters of solid coal side, and (c) support parameters of coal side.

III on the roof. The row spacing between all anchor cables is $1100 \mathrm{~mm} \times 800 \mathrm{~mm}$, and the preload is $80-100 \mathrm{kN}$.

Two-side support: the support parameters for the left side (Zones VII and VIII) and the right side (Zones IV, V, and VI) are the same. The specific support parameters are as follows: five bolts of $\Phi 22 \mathrm{~mm} \times L 2500 \mathrm{~mm}$ are arranged in each vertical row, equipped with M5 steel strip and metal netting, with a row spacing of $750 \mathrm{~mm} \times 800 \mathrm{~mm}$. The three bolts in the middle are arranged horizontally, and the bolts at both ends are tied at an angle of $15^{\circ}$ outward.
5.2.2. Support Parameters before Roadway Retaining. Notches are opened at the end of the working face. Zone I on the roof in the area to be filled is reinforced. The specific support parameters are as follows: three bolts are arranged in each row, equipped with M5 steel belt and metal netting, which are vertically arranged, with a preload of $60-80 \mathrm{kN}$ and a row spacing of $900 \mathrm{~mm} \times 800 \mathrm{~mm}$. Two anchor cables, together with $14^{\#}$ channel steel, are arranged between the two rows of bolts, which are laid out vertically, with a preload of $80-100 \mathrm{kN}$ and a row spacing of $1100 \mathrm{~mm} \times 800 \mathrm{~mm}$. 
To improve the grouting effect of hollow grouting anchor cable on the roof and prevent slurry leakage during grouting, spraying concrete to seal the surrounding rock is necessary. The guniting parameters are as follows: high-grade 425\# cement is selected, with a shotcrete thickness of 70-100 mm and strength of C20. Parameters for the hollow anchor cable grouting are as follows: high-grade 425\# cement is selected, the water-cement ratio of the slurry is $1: 2$, and the ACZ-I grouting additive is $8 \%$ of cement amount. Grouting is performed from the roof in Zone I to the roof in Zone III, with the grouting pressure reaching $6-7 \mathrm{MPa}$ and the standup pressure time of 3-5 minutes.

Solid coal side reinforcement (Zones VII and VIII): three single anchor cables of $\Phi 22 \mathrm{~mm} \times L 6300 \mathrm{~mm}$ are arranged for every two vertical rows of bolts for reinforcement. The upper anchor cables are tied at an angle of $15^{\circ}$ outward, the anchor cables in the middle are horizontally arranged, and the lower anchor cables are tied at an angle of $15^{\circ}$ outward, with a row spacing of $1000 \mathrm{~mm} \times 1600 \mathrm{~mm}$.

5.2.3. Roadside Support Parameters during Roadway Retaining. Support parameters of the filling body in Zone V are as follows: filling body width $\times$ height is designed to be $3000 \mathrm{~mm} \times 2300 \mathrm{~mm}$. A three-dimensional reinforcement framework is arranged in the filling body, and HRB400 hotrolled ribbed steel bar of $\Phi 20 \mathrm{~mm}$ is selected, with a bar spacing of $200 \mathrm{~mm}$. The special filling material for coal mines is premixed concrete, which is characterized by a fast solidification rate and high early strength. The uniaxial compressive strength of premixed concrete is $18 \mathrm{MPa}$ after 7 days and 26-30 MPa after 28 days.

Support parameters of Zone IV in the roof joint area are as follows: in the top tight filling area, three HRB400 hotrolled ribbed bars of $\Phi 32 \mathrm{~mm} \times L 2500 \mathrm{~mm}$ are installed in each row, with a row spacing of $900 \mathrm{~mm} \times 800 \mathrm{~mm}$. The reinforcement $(1500 \mathrm{~mm}$ long) embedded in the roof is anchored using capsule resin, and the exposed reinforcement (1000 $\mathrm{mm}$ long) is jointed with the upper part of threedimensional steel reinforcement framework in an overlapped manner.

Support parameters for Zone VI in the floor joint area are as follows: in the floor joint filling area, I-beams with a length of $4500 \mathrm{~mm}$ are laid out in advance, with a spacing of $800 \mathrm{~mm}$. I-beams are jointed in an overlapped manner with the three-dimensional reinforcement framework increasing the bottom contact area.

\subsubsection{Support Parameters after Roadway Retaining. In Zone} $X$ in the roadway, two auxiliary supports are laid out along the roadway strike, which are $300 \mathrm{~mm}$ and $800 \mathrm{~mm}$ away from the filling body, respectively. The specific parameters are as follows: a single column is matched using $\pi$-type steel beam of $L 4 \mathrm{~m}$, with one beam equipped with four columns, and a column spacing of $1 \mathrm{~m}$, and an initial support force is no less than $120 \mathrm{kN}$, which is used to assist in bearing the filling body, thus, achieving double control of the roof and floor.
According to the rock pressure field observation data, the roof and filling body in gob-side entry retaining in deep mines are stable after $220 \mathrm{~m}$ behind the working face. The solid coal side and floor still show an increasing trend but have a low increasing speed, indicating that the roadway retaining has entered a relatively stable period. At this time, the roof convergence is $205 \mathrm{~mm}$, the solid coal side convergence is $278 \mathrm{~mm}$, the filling body convergence is $3 \mathrm{~mm}$, and the floor convergence is $365 \mathrm{~mm}$. On the whole, the surrounding rock is subjected to smaller deformation. After dinting measures are taken, the roadway section can meet the ventilation requirements of gob-side entry retaining in stages.

\section{Conclusion}

(1) The lithologic characteristics of medium-thickness sandy mudstone and mudstone in coal measure strata in the Huainan Mining Area are analyzed from meso- and microperspectives. Results show that the clay mineral content in sandy mudstone is up to $51.46 \%$, and that in mudstone reaches $67.31 \%$. Both belong to medium-puffed soft rock. The low strength, softening, water swelling of thick mudstone as well as its cataclasis, dilatancy, and long-term creep under strong mining and high stress are the objective reasons for large deformation of the surrounding rock.

(2) The deformation and failure characteristics of thick and soft surrounding rock in gob-side entry retaining in deep mines are primarily divided into eight types: roof bending and sinking type, roof cutting along the filling body, rib spalling type, largespan roof fall type, filling body rotation type, filling body crushing type, roof step type, and cutting along the coal side. Through analysis, it is believed that, due to the weak stability of the surrounding rock-support structure and low collaborative bearing capacity of the roof side, no complete supporting structure is formed within the supporting system, causing the support body in each area to be crushed successively, which is the subjective reason for the deformation and failure of the surrounding rock.

(3) The key technology of "grading and zoning and overall reinforcement" for thick and soft surrounding rock in gob-side entry retaining in deep mines is proposed. The surrounding rock is divided into 10 supporting zones at four levels, primarily including the coupling support of three zones in the roof, the collaborative control of the two zones on the solid coal side, composite bearing of three zones beside the roadway, and auxiliary support by stages in the roadway. Coupling support is realized in each zone, forming a complete reinforced supporting structure. The research results are applied to the engineering of gob-side entry retaining in deep mines. The surrounding rock-support structure is intact and can be maintained, which is favorable for safe production in the next working face. 


\section{Data Availability}

All data used to support the findings of this study are included within the article. There are not any restrictions on data access.

\section{Conflicts of Interest}

The authors declare no conflicts of interest.

\section{Acknowledgments}

This research was financially supported by the National Natural Science Foundation of China (nos. 51804129, 51904110, and 11902123), the General Program of China Postdoctoral Science Foundation (no. 2020M671301), the Postdoctoral Science Foundation of Jiangsu Province (nos. 2019K139 and 2019Z107), the Open Foundation of Jiangsu Engineering Laboratory of Assembly Technology on Urban and Rural Residence Structure (no. JSZP201902), the Opening Project of Henan Key Laboratory of Underground Engineering and Disaster Prevention (Henan Polytechnic University), the Industry Education Research Cooperation Projects in Jiangsu Province (no. BY2020007), the Huai'an Science and Technology Plan Project (no. HAB201836), the Jiangsu Natural Science Foundation Project (BK20181061), and the 2019 Huaishang Talent Plan Program (Project leader Jingke $\mathrm{Wu}$ ).

\section{References}

[1] L. Yuan, "Strategic thinking of simultaneous exploitation of coal and gas in deep mining," Journal of China Coal Society, vol. 41, no. 1, pp. 1-6, 2016.

[2] X. G. Zheng, N. Zhang, L. Yuan et al., "Method and application of simultaneous pillar-less coal mining and gas extraction by staged gob-side entry retaining," Journal of China University of Mining \& Technology, vol. 41, no. 3, pp. 390-396, 2012.

[3] N. Zhang, C. L. Han, J. G. Han, and X.-G. Zheng, "Theory and practice of surrounding rock control for pillarless gob-side entry retaining," Journal of China Coal Society, vol. 39, no. 8, pp. 1635-1641, 2014.

[4] J. X. Zhang, H. Q. Jiang, X. X. Miao, N. Zhou, and D.-F. Zan, "The rational width of the support body of gob-side entry in fully mechanized backfill mining," Journal of Mining \& Safety Engineering, vol. 30, no. 2, pp. 159-164, 2013.

[5] X. H. Li, M. H. Ju, Q. L. Yao et al., "Numerical investigation of the effect of the location of critical rock block fracture on crack evolution in a gob-side filling wall," Rock Mechanics and Rock Engineering, vol. 49, pp. 783-797, 2015.

[6] Y. Chen, J. B. Bai, T. L. Zhu, S. Yan, S.-H. Zhao, and X.-C. Li, "Mechanisms of roadside support in gob-side entry retaining and its application," Rock and Soil Mechanics, vol. 33, no. 5, pp. 1427-1432, 2012.

[7] C. L. Han, N. Zhang, G. Li, B.-Y. Li, and H. Wu, "Stability analysis of compound bearing structure of gob-side entry retaining with large mining height," Chinese Journal of Geotechnical Engineering, vol. 36, no. 5, pp. 969-976, 2014.

[8] J. K. Wu, J. G. Kan, S. R. Xie, F.-X. Xie, and D.-D. Chen, "Failure mechanisms and control of surrounding rock of deep gob-side entry retaining in soft rock strata under high stress," Rock and Soil Mechanics, vol. 38, no. 3, pp. 793-800, 2017.

[9] M. He, G. Zhu, and Z. Guo, "Longwall mining "cutting cantilever beam theory" and 110 mining method in ChinaThe third mining science innovation," Journal of Rock Mechanics and Geotechnical Engineering, vol. 7, no. 5, pp. 483492, 2015.

[10] Y. L. Tan, F. H. Yu, J. G. Ning, and T. B. Zhao, "Design and construction of entry retaining wall along a gob side under hard roof stratum," International Journal of Rock Mechanics and Mining Sciences, vol. 77, pp. 115-121, 2015.

[11] J. Ning, J. Wang, X. Liu, K. Qian, and B. Sun, "Soft-strong supporting mechanism of gob-side entry retaining in deep coal seams threatened by rockburst," International Journal of Mining Science and Technology, vol. 24, no. 6, pp. 805-810, 2014.

[12] K. Fan, H. Liang, C. Ma, and C. Zang, "Non-harmonious deformation controlling of gob-side entry in thin coal seam under dynamic pressure," Journal of Rock Mechanics and Geotechnical Engineering, vol. 6, no. 3, pp. 269-274, 2014.

[13] D. Xue, J. Wang, H. Tu, F. Wang, and J. Zhao, "Deformation failure mechanism and application of the backfill along the goaf-side retained roadway," International Journal of Mining Science and Technology, vol. 23, no. 3, pp. 329-335, 2013.

[14] H. P. Kang, "Sixty years development and prospects of rock bolting technology for underground coal mine roadways in China," Journal of China University of Mining \& Technology, vol. 45, no. 6, pp. 1071-1081, 2016.

[15] J. H. Wang, "Analysis on mechanism and effect of rock bolts and cables in gate road with coal seam as roof," Journal of China Coal Society, vol. 31, no. 1, pp. 1-7, 2012.

[16] M. C. He and Z. Guo, "Mechanical property and engineering application of anchor bolt with constant resistance and large deformation," Chinese Journal of Rock Mechanics and Engineering, vol. 33, no. 7, pp. 1297-1308, 2014.

[17] G. C. Zhang, F. L. He, H. G. Jia, and Y.-h. Lai, "Analysis of gate road stability in relation to yield pillar size: a case study," Rock Mechanics and Rock Engineering, vol. 50, no. 5, pp. 1-16, 2017.

[18] Q. Liu, C. Lu, B. Liu, and X. Liu, "Research on the grouting diffusion mechanism and its application of grouting reinforcement in deep roadway," Journal of Mining \& Safety Engineering, vol. 31, no. 3, pp. 333-339, 2014.

[19] S.-c. Li, H.-t. Wang, Q. Wang et al., "Failure mechanism of bolting support and high-strength bolt-grouting technology for deep and soft surrounding rock with high stress," Journal of Central South University, vol. 23, no. 2, pp. 440-448, 2016.

[20] Y. Chen, Q. Meng, G. Xu, H. Wu, and G. Zhang, "Boltgrouting combined support technology in deep soft rock roadway," International Journal of Mining Science and Technology, vol. 26, no. 5, pp. 777-785, 2016.

[21] Q. L. Yao, B. Li, S. J. Ren et al., "Application of hollow grouted anchor cable in soft coal roadway under high in-situ stress," Journal of Mining \& Safety Engineering, vol. 28, no. 2, pp. 198-203, 2011.

[22] L.-g. Wang, H.-l. Li, and J. Zhang, "Numerical simulation of creep characteristics of soft roadway with bolt-grouting support," Journal of Central South University of Technology, vol. 15, no. S1, pp. 391-396, 2008.

[23] R. Pan, Q. Wang, B. Jiang et al., "Failure of bolt support and experimental study on the parameters of bolt-grouting for supporting the roadways in deep coal seam," Engineering Failure Analysis, vol. 80, no. 80, pp. 218-233, 2017.

[24] M. C. He, Concept and Classification of Soft Rock, pp. 47-57, China Coal Industry Publishing House, Beijing, China, 1999. 
[25] J. B. Bai, H. Q. Zhou, C. J. Hou, X. Z. Tu, and D. Z. Yue, "Development of support technology beside roadway in goafside entry retaining for next sublevel," China University of Mining and Technology, vol. 33, no. 2, pp. 183-186, 2004.

[26] J. G. Kan, L. Yuan, and N. Zhang, "Bearing capacity of backfilling area roof in gob-side entry retaining," Journal of China Coal Society, vol. 36, no. 9, pp. 1429-1434, 2011. 